\title{
The ulnar artery pseudoaneurysm
}

\author{
Joel Woodley-Cook, Magdalena Konieczny, Martin Simons
}

Department of Medical Imaging, University of Toronto, Toronto, Ontario, Canada

\section{Correspondence to Dr Joel Woodley-Cook, jwoodleycook@gmail.com}

Accepted 25 September 2015

\section{DESCRIPTION}

Three years following a blunt injury to his hand, a 44-year-old man presented with a persistently painful focal area of his left palm at the base of his thumb. Physical examination revealed a small painful pulsatile mass at the base of his left hypothenar eminence. His radial pulse was normal and he had a normal capillary refill of his ulnar and radial-sided digits. There was no evidence of digital ischaemia.

MRI demonstrated a saccular outpouching at his distal ulnar artery (figure 1A, arrow), which on Doppler ultrasound demonstrated the so-called 'yin-yang' sign (figure 1A). These imaging findings and history are classic for a traumatic arterial pseudoaneurysm. Diagnostic angiography confirmed the pseudoaneurysm (figure 1B, white arrow; and video 1) and also demonstrated a normally opacified radial artery (figure 1B, black arrow) and palmar arches (figure 1B, asterisks). The pseudoaneurysm was initially treated with a direct thrombin injection, which initially thrombosed the pseudoaneurysm, but this reopened within a week. The patient was re-treated using transarterial coil embolisation from a brachial artery approach. A postcoiling angiogram demonstrated cessation of the pseudoaneurysm filling (figure $1 \mathrm{C}$, arrow, and video 2 ).

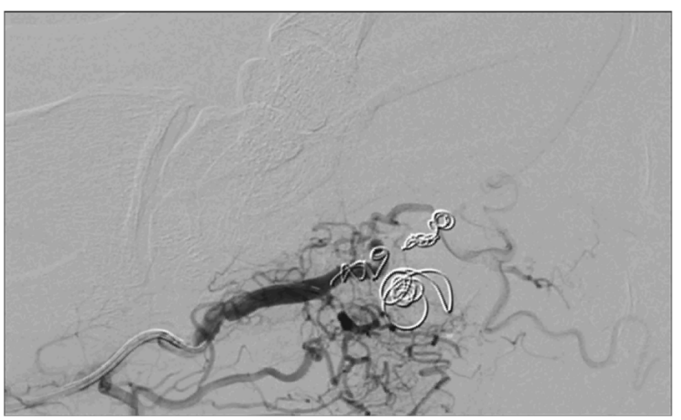

Video 1 Precoiling digitally subtracted arteriogram showing the filling of the ulnar artery pseudoaneurysm.

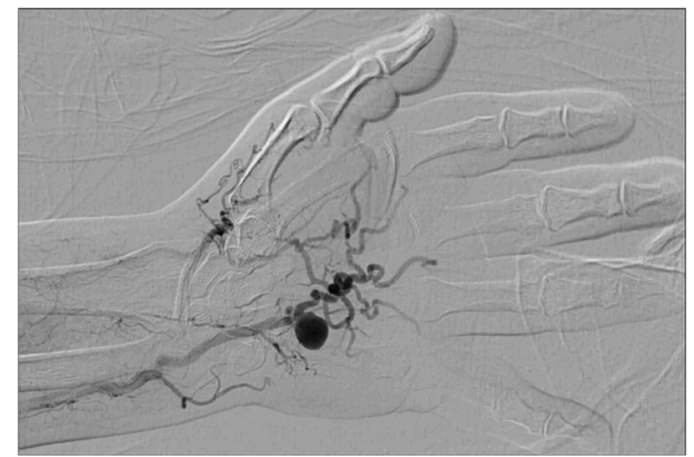

Video 2 Digitally subtracted arteriogram showing the lack of pseudoaneurysm filling after coiling distal, proximal, and within the pseudoanuerysm sac.

Traumatic arterial pseudoaneurysms are uncommon lesions that usually result from a blunt or penetrating injury. ${ }^{1}$ The thrombus that can develop within the pseudoaneurysm can be a source for embolisation, putting the distal tissue at risk for ischaemia/necrosis.

Following coiling, our patient's symptoms resolved immediately and arterial Doppler

\section{Learning points}

- Pseudoaneurysm is a term to describe either an outpouching of a blood vessel that involves the innermost layers of a blood vessel (intuma and media) with an intact outer layer (adventitia) or damage to all three layers with bleeding being contained by a surrounding clot or structures.

- The 'yin-yang' sign on colour Doppler sonography is classic for a pseudoaneurysm. ${ }^{1}$

- Percutaneous thrombin injection or transarterial coil embolisation are two options to treat pseudoaneurysms. $^{12}$
To cite: Woodley-Cook J, Konieczny M, Simons M. BMJ Case Rep Published online: [please include Day Month Year] doi:10.1136/ bcr-2015-212791
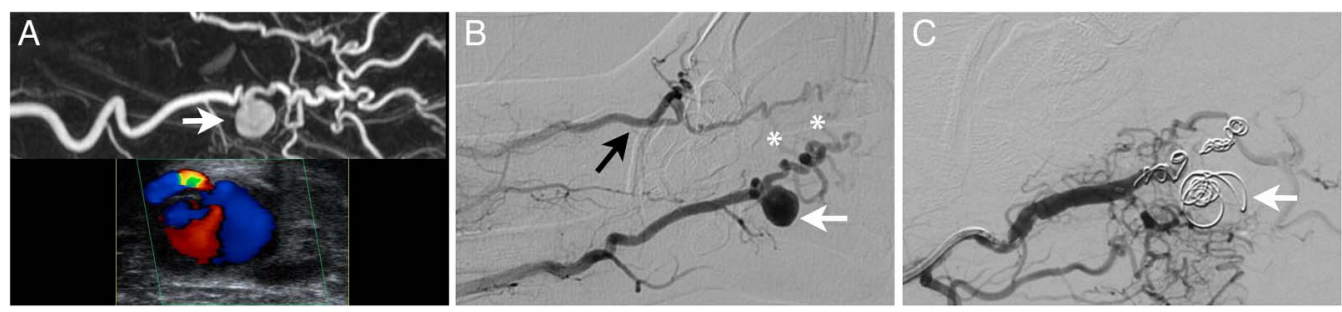

Figure 1 (A) (upper): MR angiogram demonstrating a saccular outpouching of the distal ulnar artery (arrow) consistent with a pseudoaneurysm. (A) (lower): Classic 'yin-yang' sign flow of blood within the pseudoaneurysmal sac on colour Doppler sonography. (B) Arteriogram demonstrating the ulnar artery pseudoaneurysm (arrow). (C) Postcoiling arteriogram showing the lack of pseudoaneurysmal filling (arrow). 
ultrasound at 1 week postcoiling showed a lack of blood flow within the remnant pseudoaneurysmal sac and normal flow of all digital arteries.

Contributors JW-C wrote the paper and performed the procedure as the clinical fellow. MK assisted during the procedure and edited the paper. MS supervised the procedure and edited the paper.

Competing interests None declared.

Patient consent Obtained.
Provenance and peer review Not commissioned; externally peer reviewed.

\section{REFERENCES}

1 Krueger K, Zaehringer M, Strohe D, et al. Postcatheterization pseudoaneurysm: results of US-guided percutaneous thrombin injection in 240 patients. Radiology 2005;236:1104-10.

2 Kruger K, Zähringer M, Söhngen FD, et al. Femoral pseudoaneurysms: management with percutaneous thrombin injections-success rates and effects on systemic coagulation. Radiology 2003;226:452-8.

Copyright 2015 BMJ Publishing Group. All rights reserved. For permission to reuse any of this content visit http://group.bmj.com/group/rights-licensing/permissions.

BMJ Case Report Fellows may re-use this article for personal use and teaching without any further permission.

Become a Fellow of BMJ Case Reports today and you can:

- Submit as many cases as you like

- Enjoy fast sympathetic peer review and rapid publication of accepted articles

- Access all the published articles

- Re-use any of the published material for personal use and teaching without further permission

For information on Institutional Fellowships contact consortiasales@bmjgroup.com

Visit casereports.bmj.com for more articles like this and to become a Fellow 